\title{
سلطة المتخيل: نحو مقاربة تأويليّة للخطاب
}

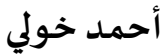 \\ جامعة النجاح الوطنية- فلسطين
}

ahmadkhouli94@gmail.com

تُحاجُ هذه الدّراسة بفرضيّة مفادها أنّ الخطاب، أيّ خطاب، ومهما كان تجنيسه، لا يمكنه الفكاك من ربقة المتخيَّل

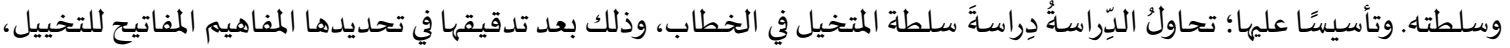

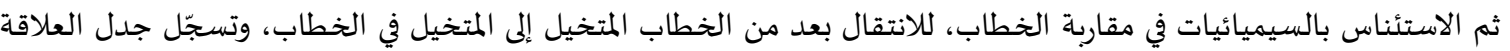
بينهما، حتى تنتهي إلى تسطير الأثر الذي سيتركه ذلكم الانتقال على صعيد تلقي الخطاب وتأويله.

الكلمات المفتاحية: الخطاب، المتخيل، التأويل.

\section{(ब) (1)}

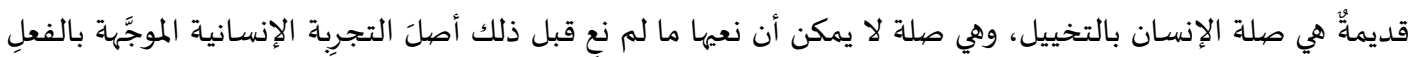

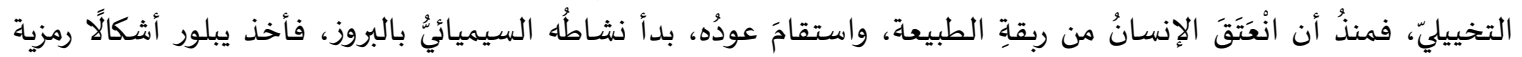

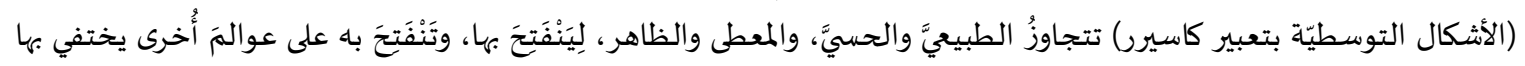

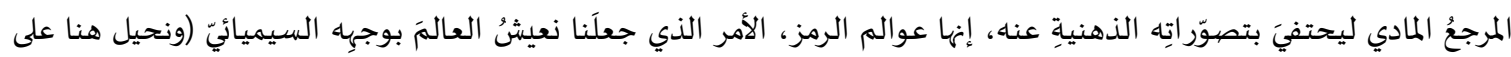

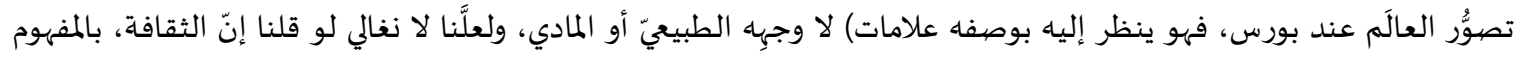

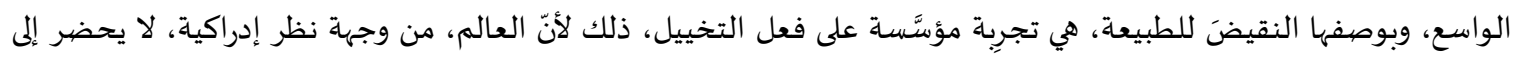

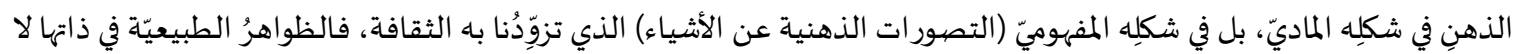

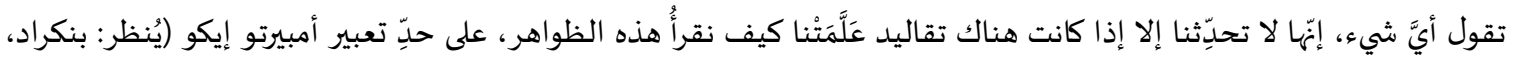

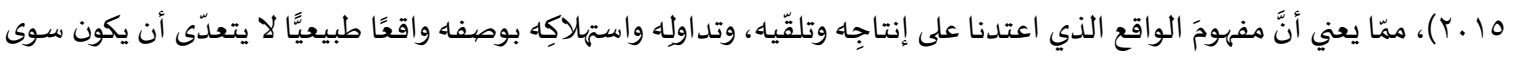
الواقع الذي جرى تسنينه ثقافيًًا.

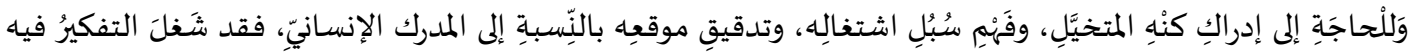

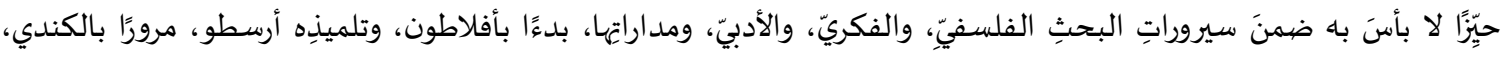

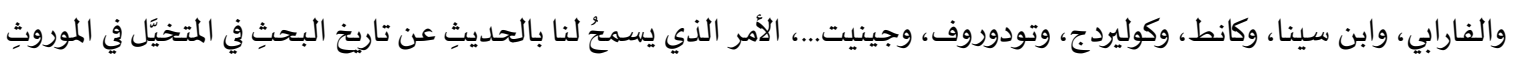

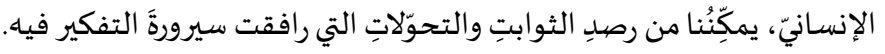

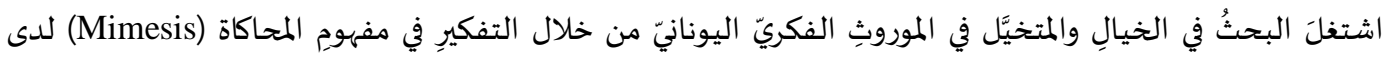

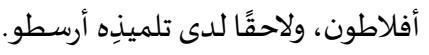

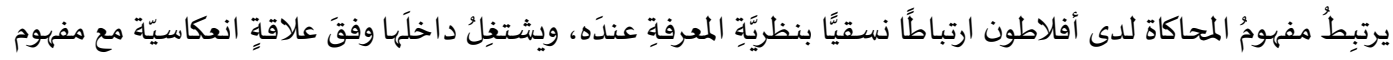

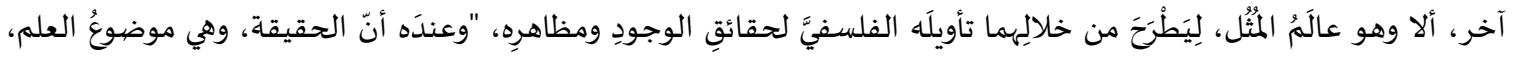

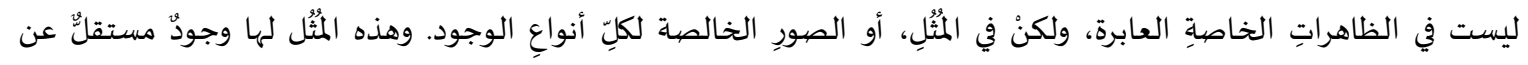

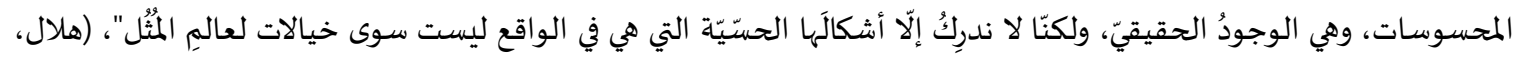




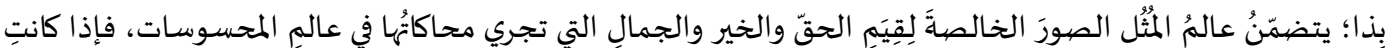

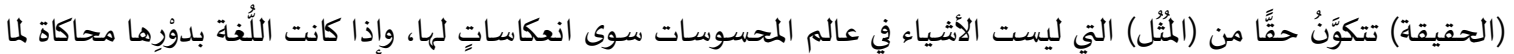

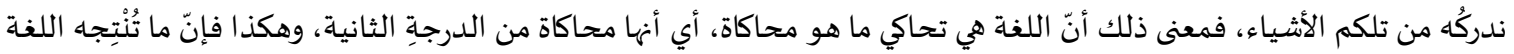

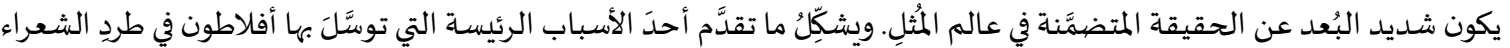
من جمهوريّتِه.

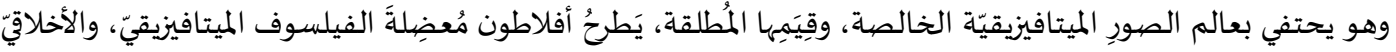

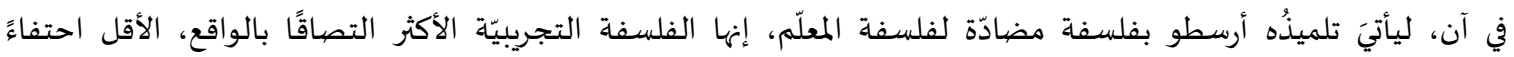

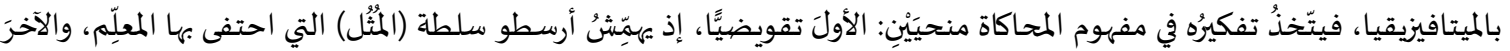

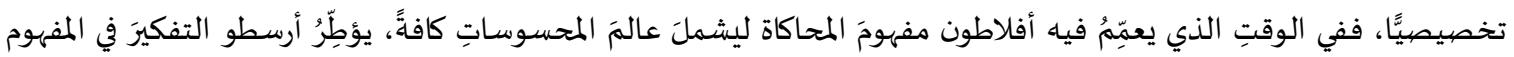
ضمن نظريةِ الفنون. وإن كانت المحاكاة أحدَ أسباب رفضِ أفلاطون الشعر والشعراء لكوْهَه يُحاكون ما هو محاكاة، فإنَّ أرسطو يرى "أنَّ الشاعر

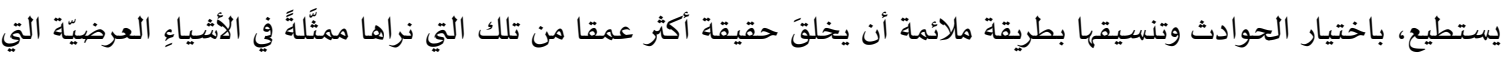

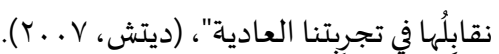

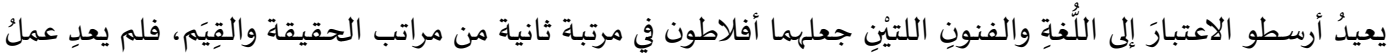

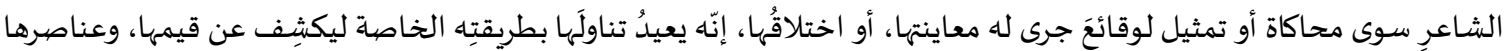

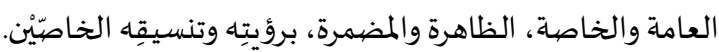

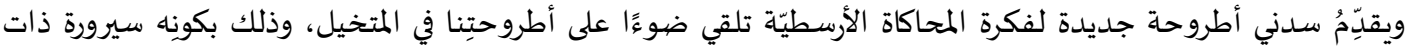

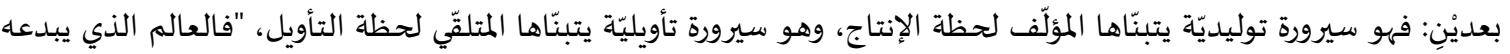

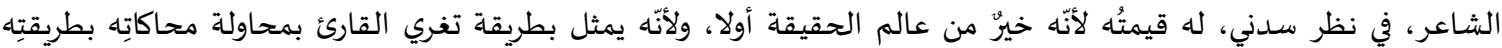

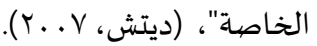

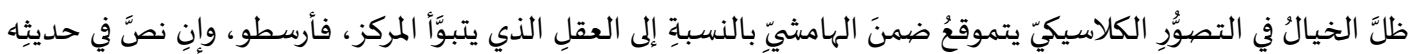

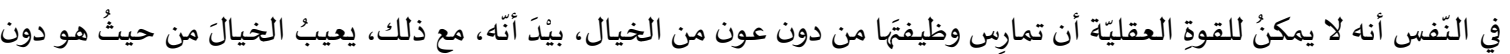

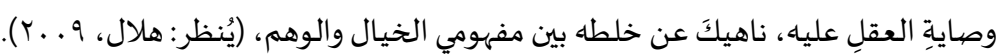

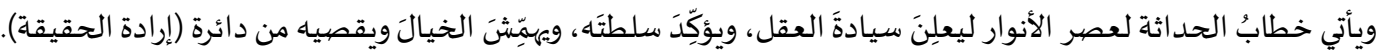

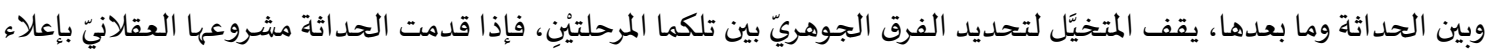

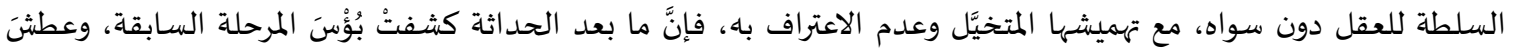

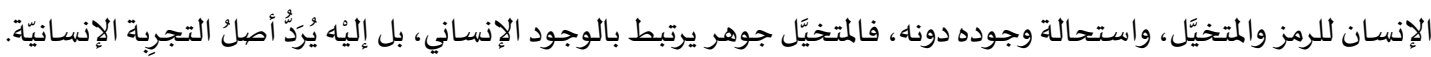

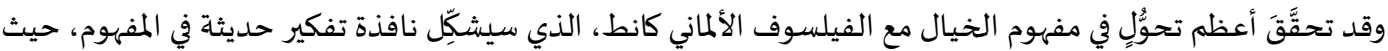

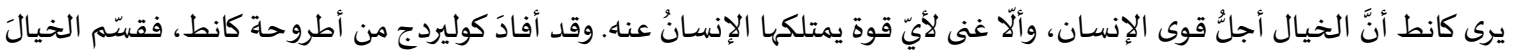

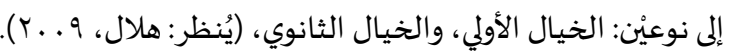

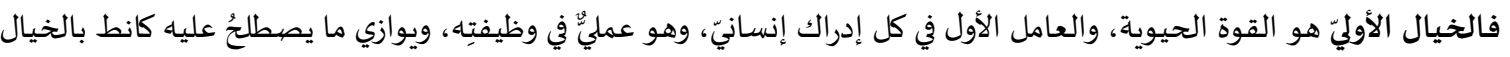
الإنتاجي.

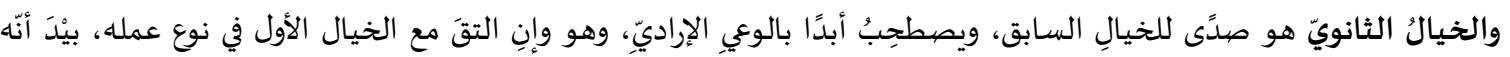

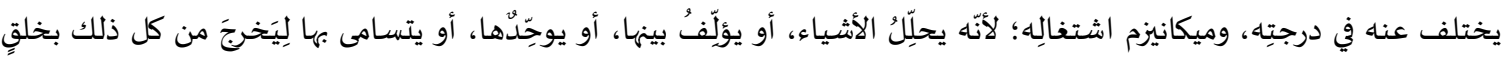

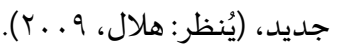

\section{1. الخطاب: جدلُ التمثيلِ والتخييل:}

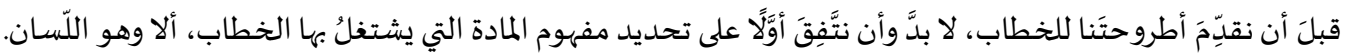

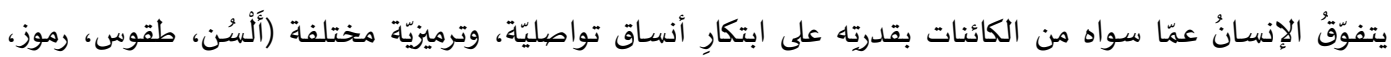

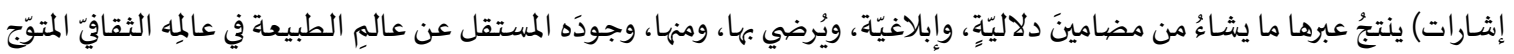

بالعلامات، المحتفي بدلالاتها، وظظلال دلالاتها. 


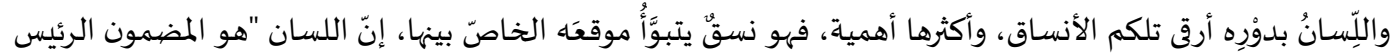

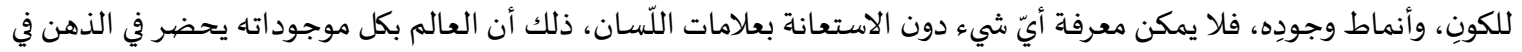

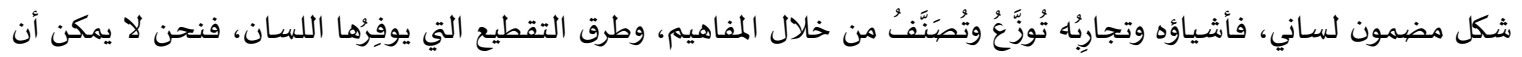

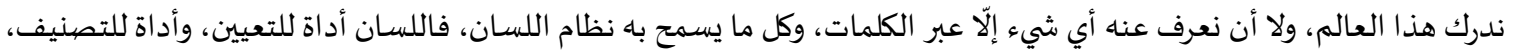

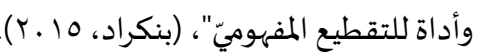

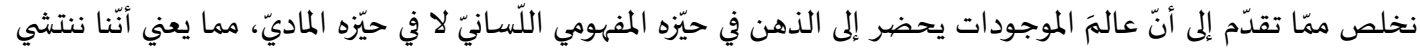

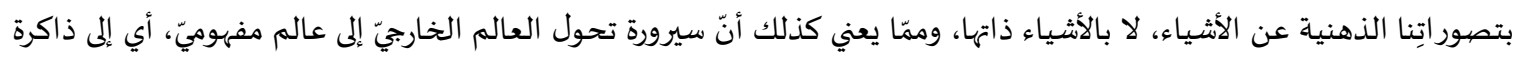

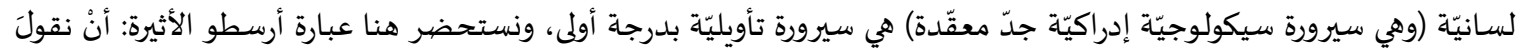

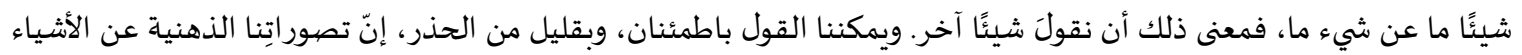

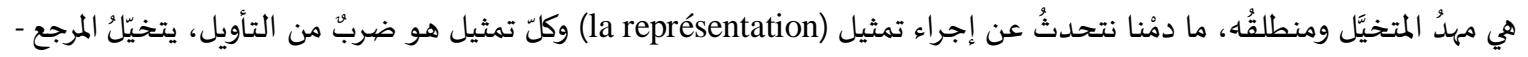

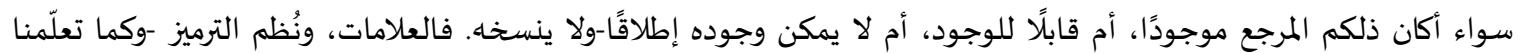

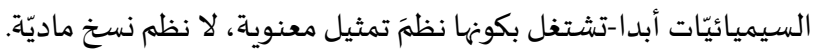

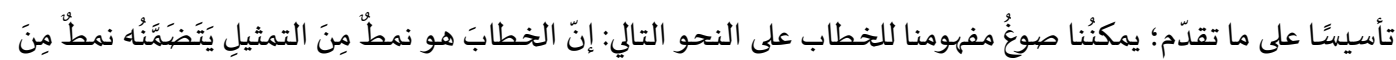

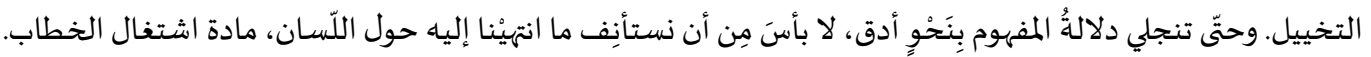

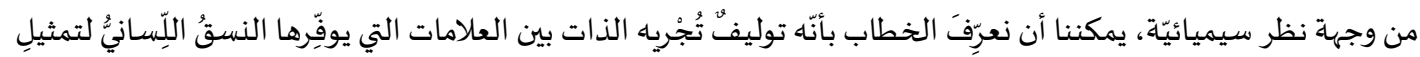

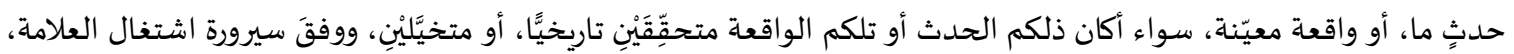

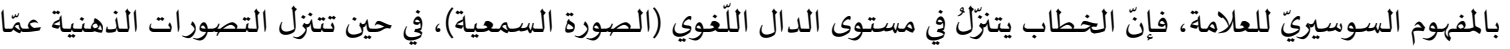

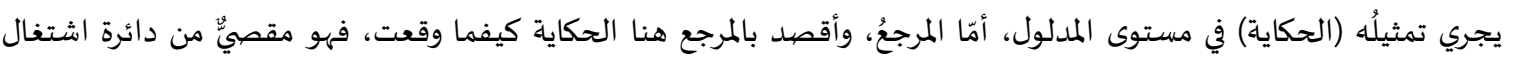

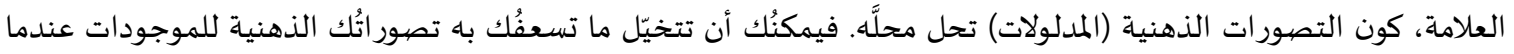

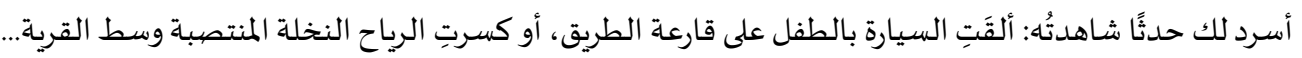

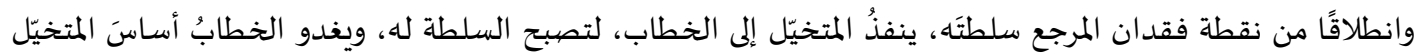

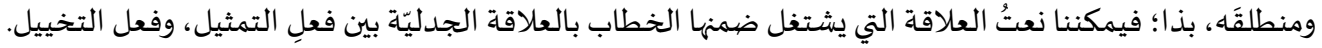

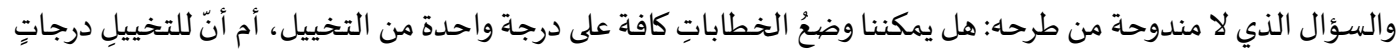

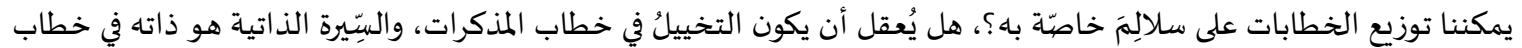

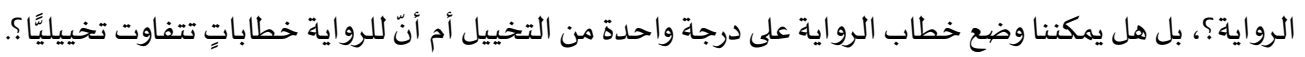

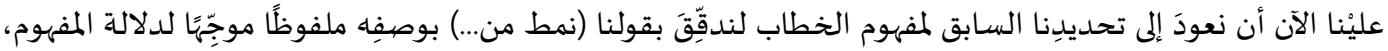

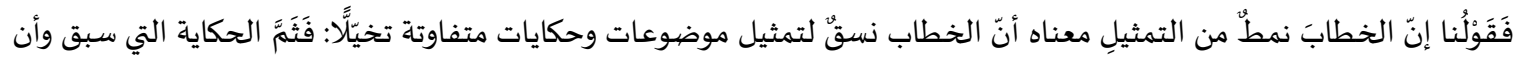

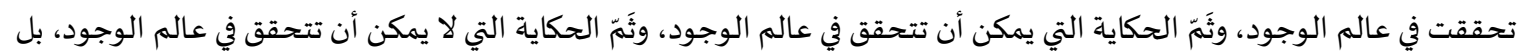

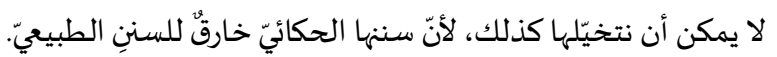

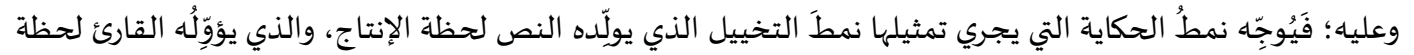

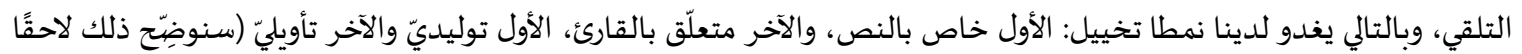
عندما نستثمر مفهوم العلامة عند بورس في مقاربة الخطاب).

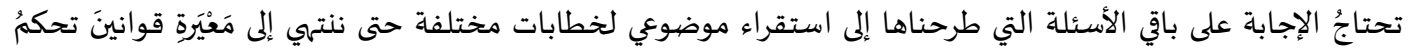

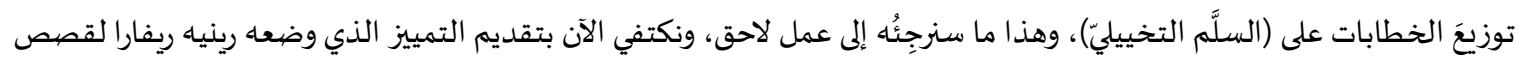

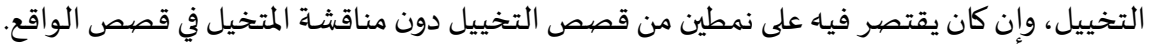

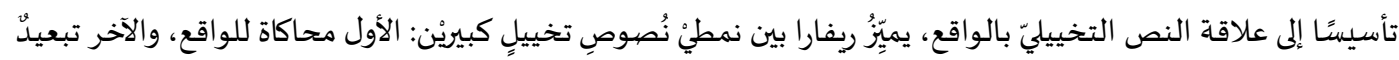

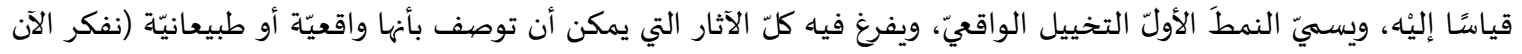

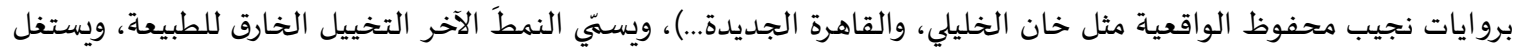

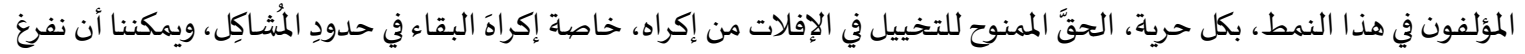

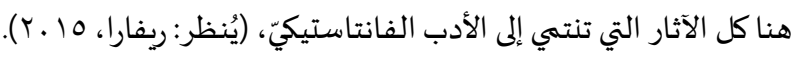




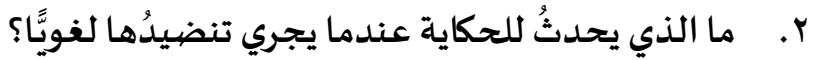

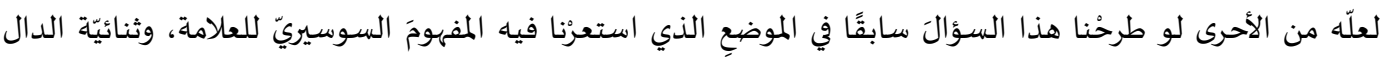

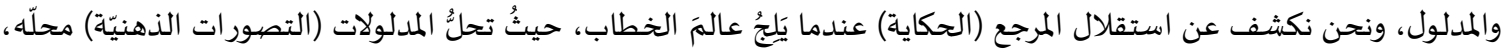

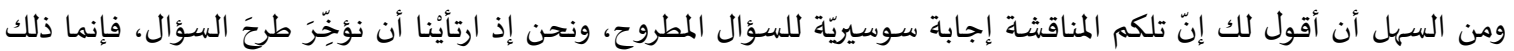

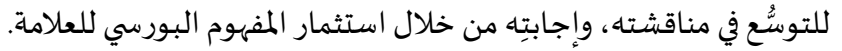

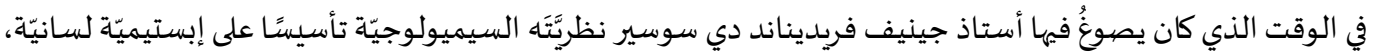

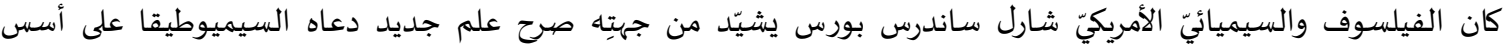

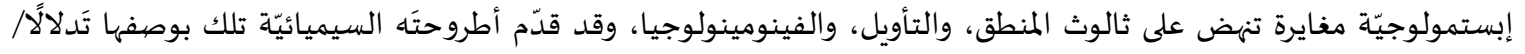
سيميوزيس (Semiusys)، أي سيرورة لإنتاج الدلالة ونمط تداولها، واستهلاكها، إنهّا بعبارة واحدة تصوُّرٌ متكاملُ للعالم.

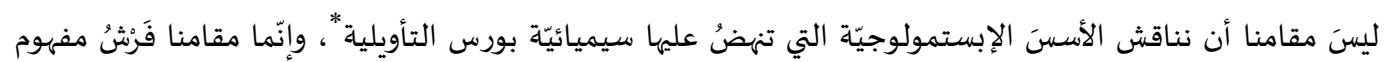

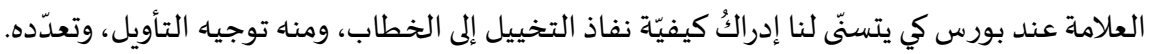

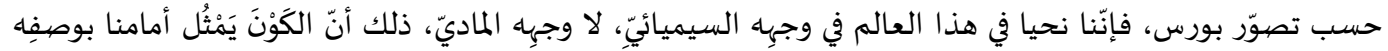

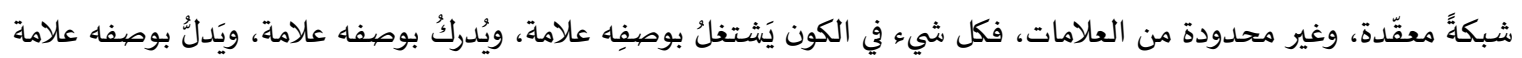

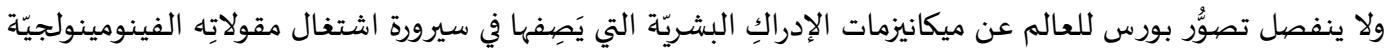

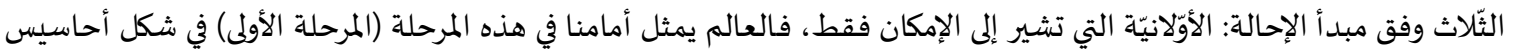

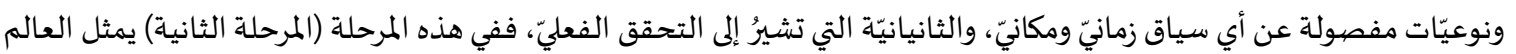

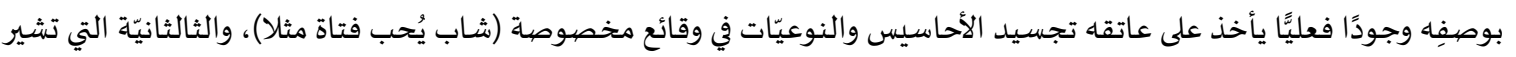

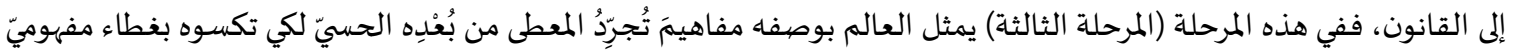

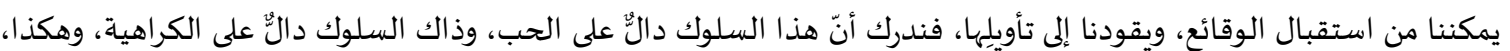

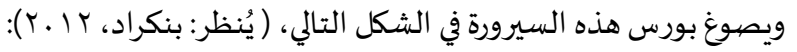

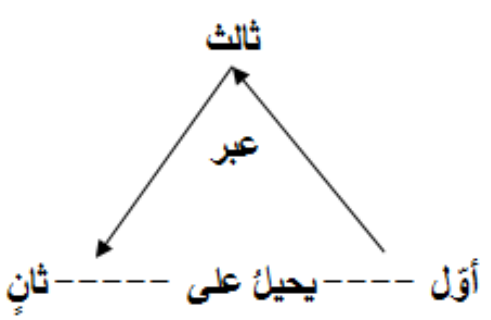

يوجِّه اشتغالُ فعل الإدراك الإنسانيّ الإحاليّ الذي تصفه المقولات (أوّل يحيلُ على ثانٍ عبر ثالث هو القانون) اشتغالَ العلامةِ

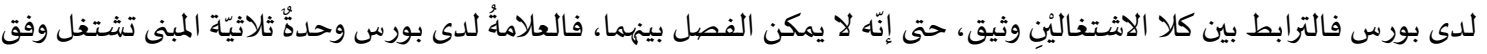

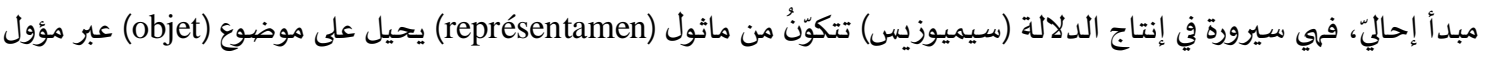
(interprétant)

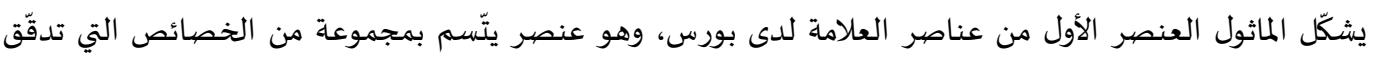

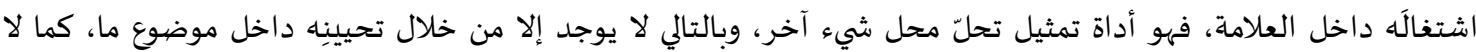

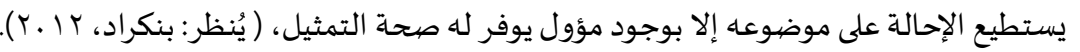

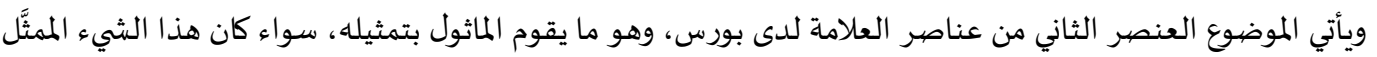

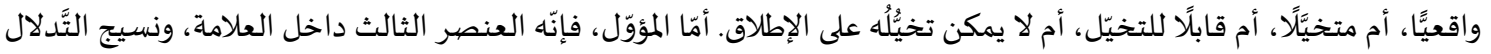

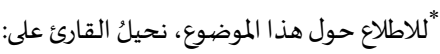

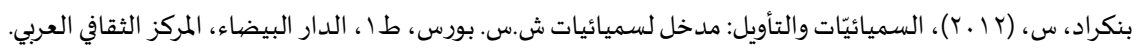

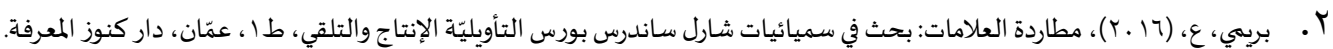


(السيميوزيس)، وهو عماد العلامة وبؤرتها الرئيسة. إنه يشكل التوسط الإلزاميّ الذي يجعل الانتقال من الماثول إلى الموضوع أمرًا

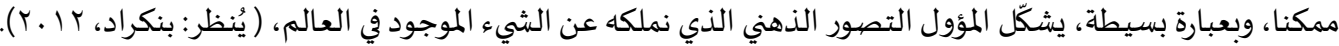
ويصوغ بورس سيرورة اشتغال العلامة في الشكل التالي:

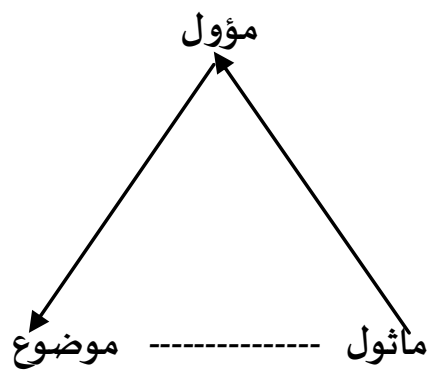

(يشير الخط المتقطع إلى أن العلاقة بين الماثول والموضوع ليست مباشرة، بل تمر عبر المؤول).

والسؤال الذي تنتظرُ مني طرحَه: كيف يمكننا استثمارُ مفهوم العلامة لدى بورس، وسيروة التَّدلال في تحديد نفاذ المتخيّل إلى

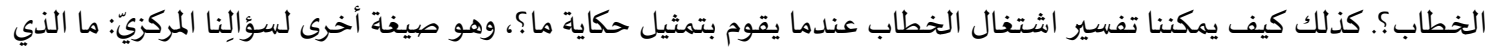

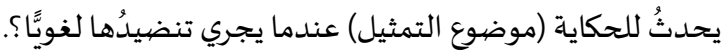

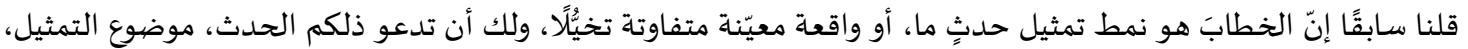

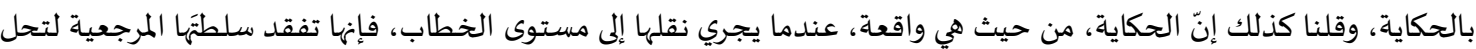
مححلَّها تصوّر اتنا الذهنية عنها.

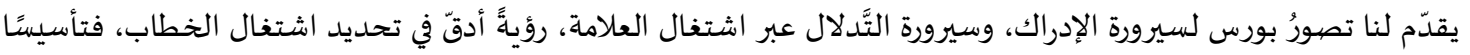

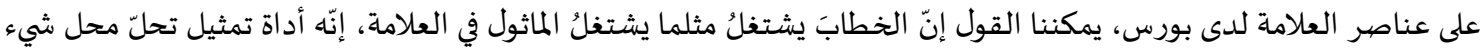

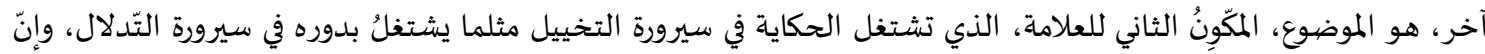

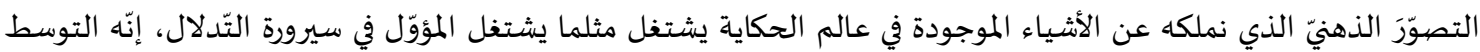

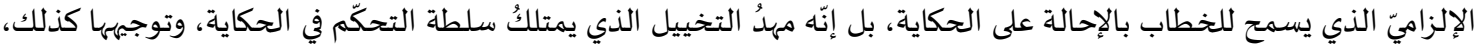

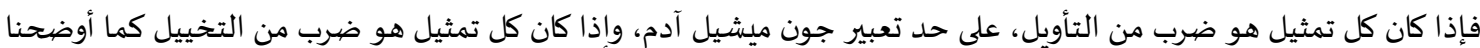

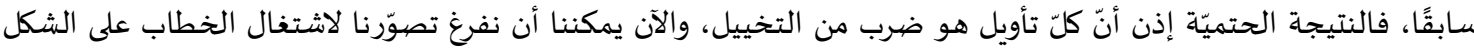

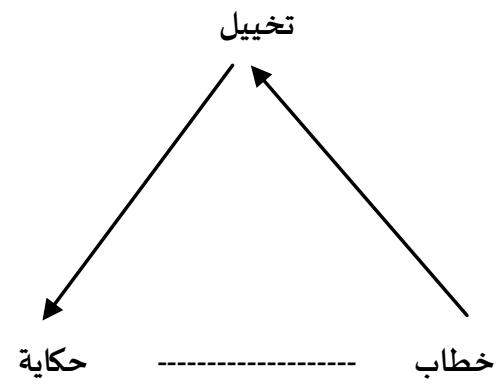

(يشير الخط المتقطع إلى أن العلاقة بين الخطاب والحكاية ليست مباشرة، بل تمر عبر التخييل).

يشكِّل المؤول عمادَ اشتغال الخطاب، وأساس تلقّيه وتأويله كذلك، فهو ما يتحكّم في سيرورة التّدلال، وانتقاءِ المعنى، ووضعِِه

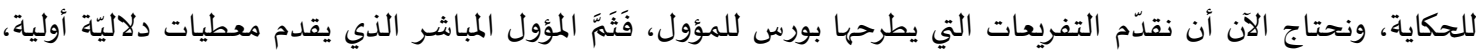

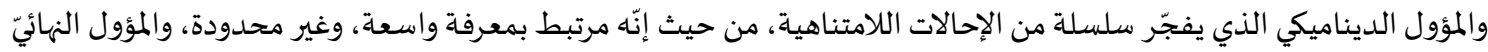

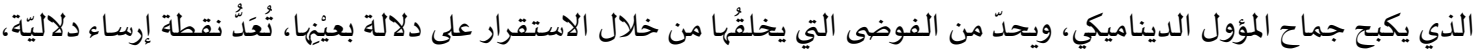

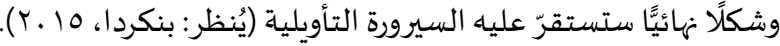


فالمؤول إذن ما يكون مسؤولًا عن نمطِ تصوُّرنا الحكاية، وبالتالي نمط تخيُّها، وتأويلها، فإذا كان المؤول المباشر يقدّم للحكاية

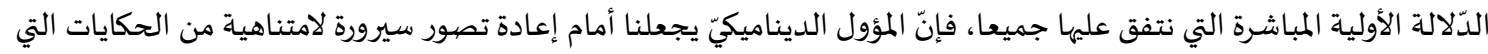

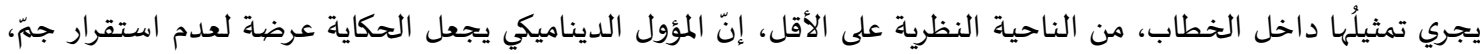

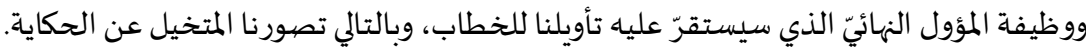

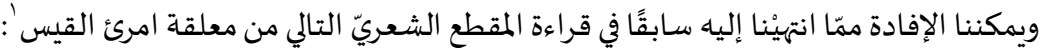

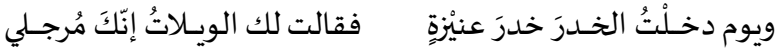

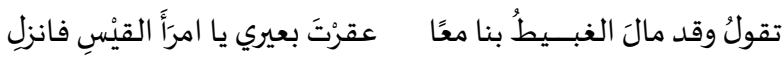

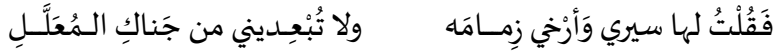

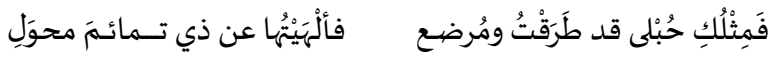

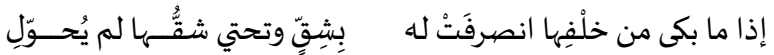

وسؤالُ التلقّي الذي سيطرح نفسَه: كيفَ يمكننا التفاهمُ مع نص امرئ القيس، والملك الضيلّيل ونصهاه يبعدان منّا . .17 عامٍ

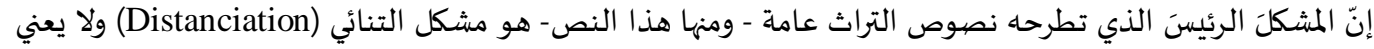

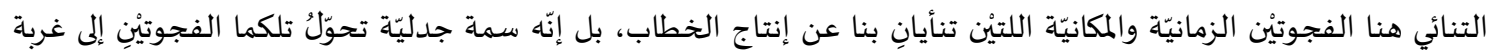

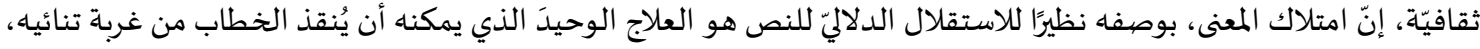

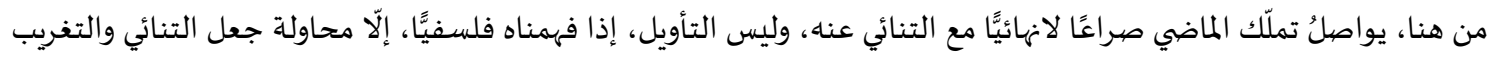

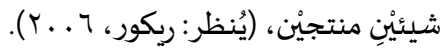

دأبت نصوص التراث الشارحة للمعلقات على تلقّي خطاب حكاية امرئ القيس مع محبوبتِهِ عنيزة بتأويل الحكاية تأويلًا

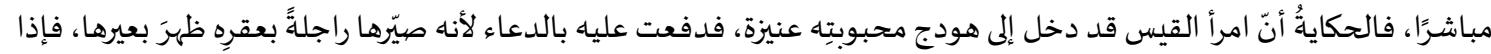

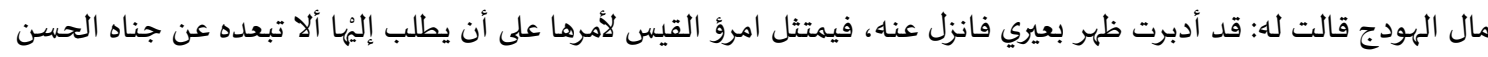

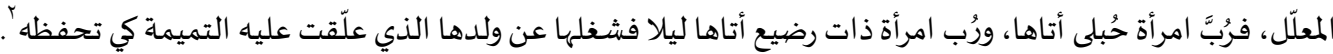

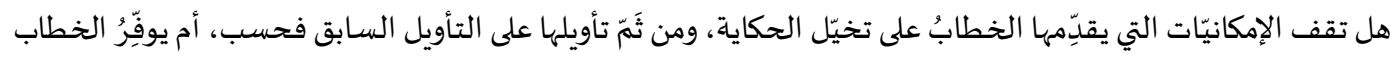

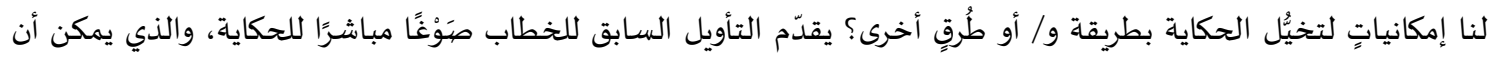

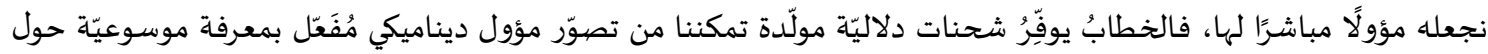

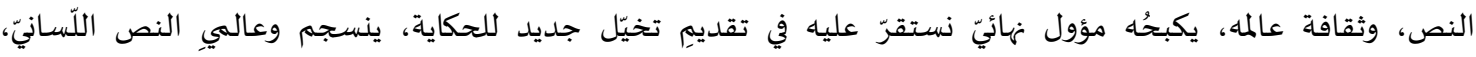
والسوسيوثقافيّ.

ألا تتفق في طرح الأسئلة التالية: ما الخطبُ العظيم الذي جناه امرؤ القيس حتى ينال دعاء عنيزة عليه بالويلات؟، لماذا

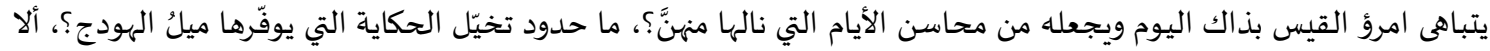

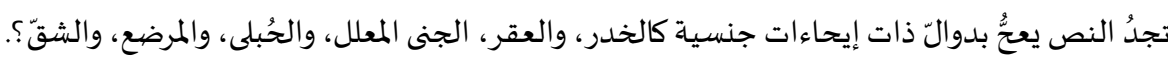

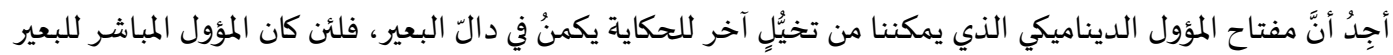

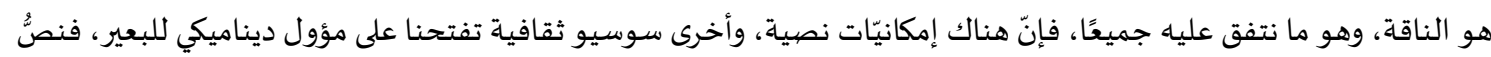

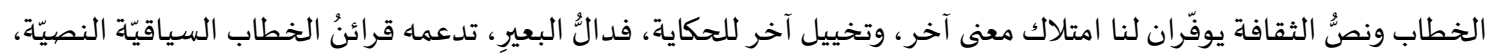

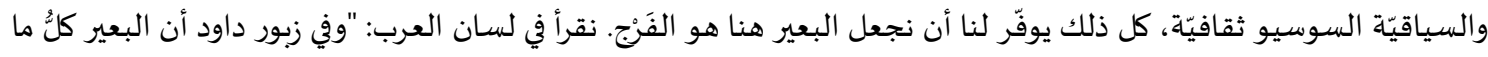

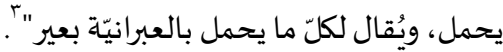

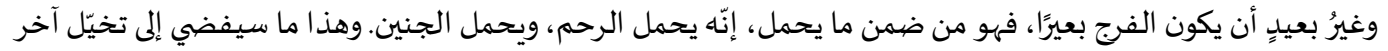

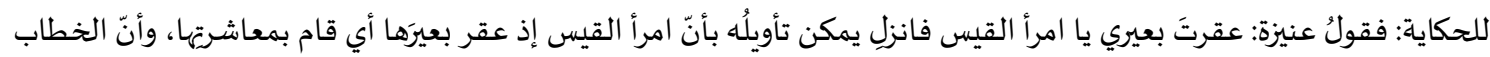

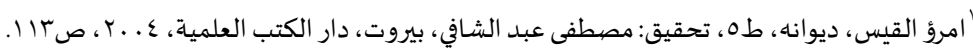

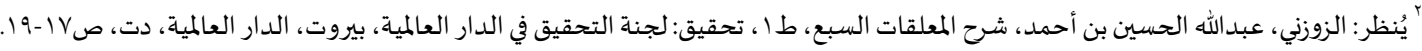

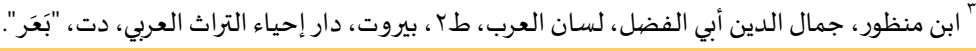

V. 


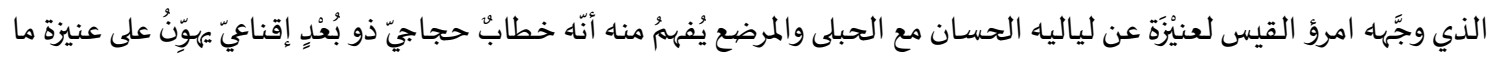
فعله امرؤ القيس بها.

ويمكن الإفادةُ من التصوّرات الحديثة لمقاربة الاستعارة في دعم تأويلنا السابق، فإن كانت المقاربة الكلاسيكيّة تنظر إلى

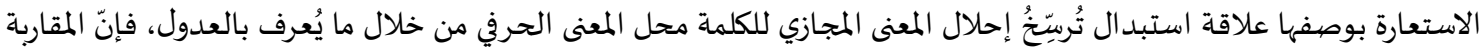

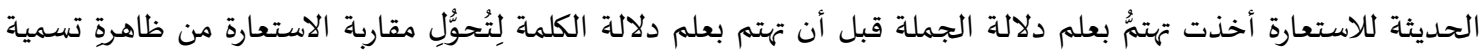

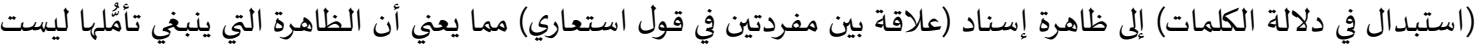

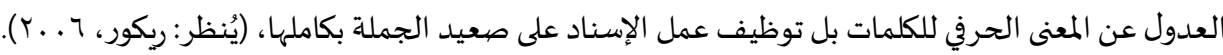

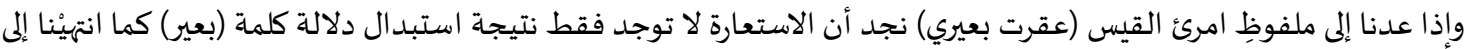

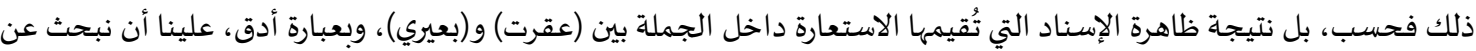

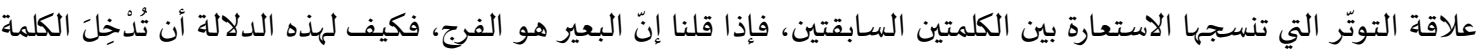

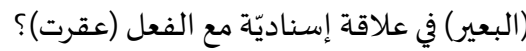

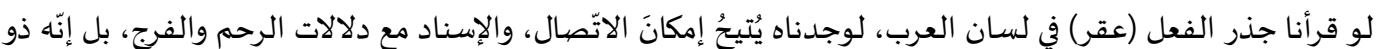

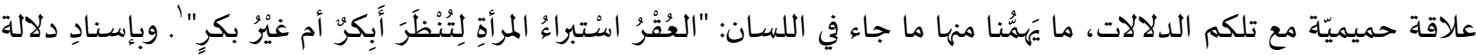

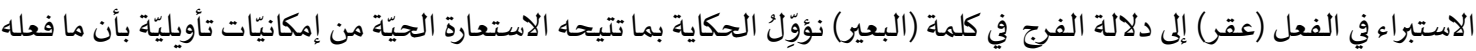

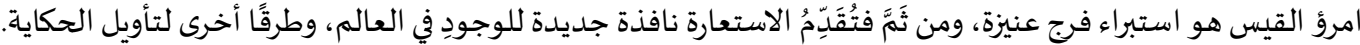

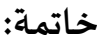

تخلصيُ الدراسة إلى نتيجة مفادُها أنّ كلَّ سيرورة تأويليّة هي سيرورة تخييليَّة بالضّرورة، فالتّخييل هو المستوى التوسّطيّ

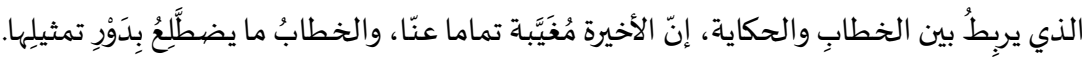

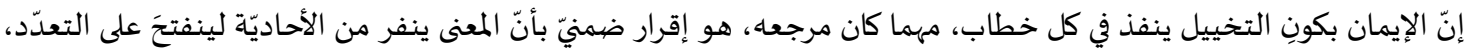

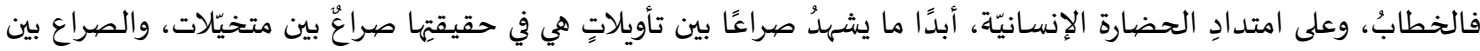

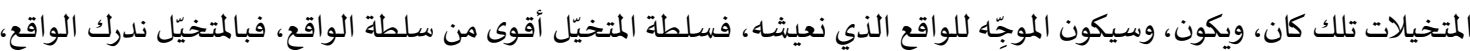
ونبني تصهور اتنا عنه، ونعيدُ إنتاجَه.

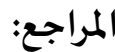

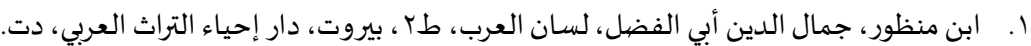

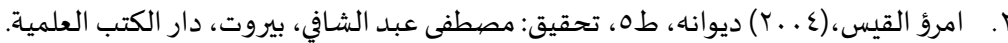

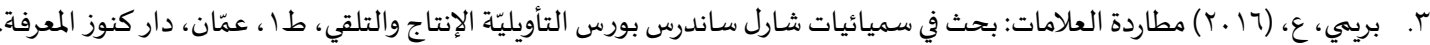

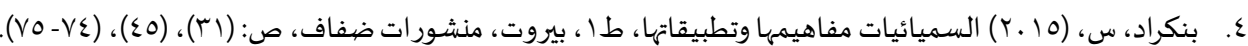

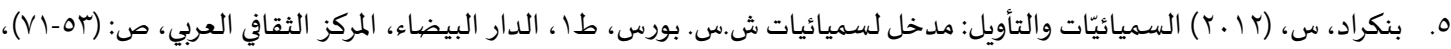
$(\wedge 9-\Lambda)$ ، ( ( 9 )

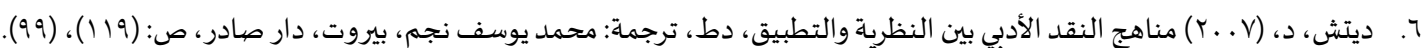

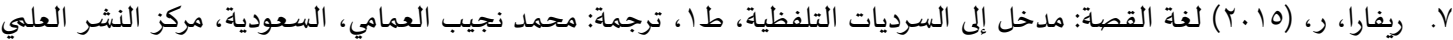

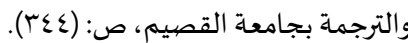

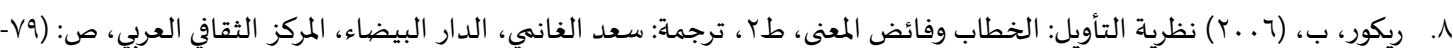

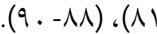

9. الزوزني، عبدالله الحسين بن أحمد، شرح المعلقات السبع، طا ، تحقيق: لجنة التحقيق في الدار العالمية، بيروت، الدار العالمية، دت.

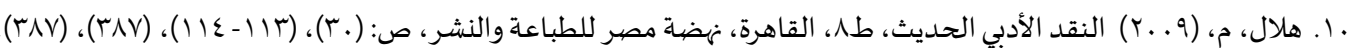

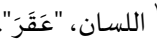




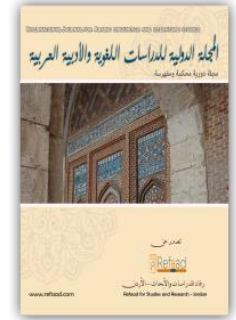

\title{
The Rule of Imaginary: Towards an Interpretive Approach to Discourse
}

\author{
Ahmad Khouli \\ Al -Najah National University- Palestine \\ ahmadkhouli94@gmail.com
}

Abstract: This study argues that discourse, whatever its genre, is inseparable from the power of imagination; accordingly, trying to study the power of the imagination in discourse, through the examination in identifying the key concepts of the imagination, and then relying on the semiotics in the approach of discourse, to move from the imaginary speech to the imaginary in the speech, and identifying the relation between them , and ultimately to highlight the impact that will leave on the transition on receiving and interpreting the discourse.

Keywords: Discourse, Imagination, Interpretation.

\section{References:}

[1] Ạbn Mnẓwr. Jmạl Ạldyn Ạ̉by Ạlfụl, Lsạn Ạl'rb, Ṭ2, Byrwt, Dạr Ạ̣yạ’ Ạltrạth Ạl 'rby, Dt.

[2] Ạlzwzny. 'bdạllh Ạlḷ̣syn Bn Ạhmd, Sḥrḥ Ạlm lqạt Ạlsb', Ț1, Tḥqyq: Ljnt Ạltḥyq Fy Ạldạr Ạl 'ạlmyh, Byrwt, Ạldạr Ạl 'ạlmyh, Dt.

[3] Ạmrw̉ Ạlqys, Dywạnh, Ț5, Tḥqyq: Mṣțfy ‘bd Ạlshạafy, Byrwt, Dạr Ạlktb Ạl 'lmyh, (2004)

[4] Bnkrạd. S, Ạlsmyậyyạt Mfạhymhạ Wtṭbyqạthạ, Ṭ1, Byrwt, Mnshowrạt Ḍfạf, (2015), pp. 31, 45, 74- 75 .

[5] Bnkrạd. S, Ạlsmyạyyạạt Wạltạ̉wyl: Mdkhhl Lsmyậyyạt Sh̆.S. Bwrs, T1, Ạldạr Ạlbyḍạa', A.lmrkz A.lthqạfy Al'rby, (2012), pp. 53-71, 79, 81- 89

[6] Brymy. ', Mțardë Ạl'lạmạt: Bḥtḥ Fy Smyậyạat Shạrl Sạndrs Bwrs Ạltạ̉wylỹh ẠlạNtạj Wạltlqy, Ṭ1, 'mạn, Dạr Knwz Ạlm rrfh, (2016)

[7] Dytsh̆. D, Mnạhj Ạlnqd Ạlạ̉dby Byn Ạlnẓryh Wạltṭbyq, Dṭ, Trjmü: Mḥmd Ywsf Njm, Byrwt, Dạr Șạdr, (2007), pp. 119, 99.

[8] Hlạl. M, Ạlnqd Ạlạ̉dby Ạlḥ̣dytḥ, Ṭ8, Ạlqạhrh, Nhḍ̈ Mṣr Llțbạ h W Wạlnsḥr, (2009), pp. 30, 113- 114, 387, 387.

[9] Ryfạrạ. R, Lgḥ̈t Ạlqșh: Mdkhl ALy Ạlsrdyạt Ạltlfzyhh, Ṭ1, Trjmï: Mḥmd Njyb Ạl'mạmy,

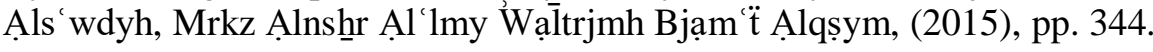

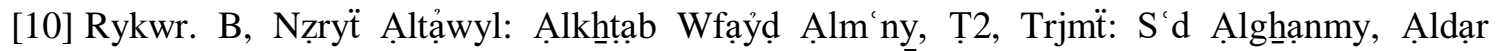
Ạlbyḍạ', Ạlmrkz Ạlthquafy Ạl'rby, (2006), pp. 79- 81, 88- 90. 